\title{
O EPIFENÔMENO DA ALTERNÂNCIA DE VALÊNCIA NA LÍNGUA TENETEHÁRA (TUPÍ-GUARANÍ)
}

\section{THE EPIPHENOMENON OF VALENCE ALTERNATION IN TENETEHÁRA LANGUAGE (TUPÍ-GUARANÍ)}

\section{Ricardo Campos de Castro*}

RESUMO: Este artigo tem como objetivo principal exibir três mecanismos de alternância de valência na língua Tenetehára (TupíGuaraní). O primeiro processo analisado é a incorporação nominal sem diminuição de valência. A segunda construção investigada é a voz antipassiva. Mostraremos que um verbo transitivo pode ser antipassivizado quando recebe o morfema $\{-\operatorname{pur}(\mathrm{u})\}$. Além disso, defendemos que as construções antipassivas não são exclusivas de línguas ergativas. Finalmente, o terceiro fenômeno analisado é o aumento de valência por meio do morfema aplicativo $\{-\operatorname{er}(\mathrm{u})\}$. Baseado na proposta de Pylkkänen (2002) e Vieira (2001, 2010), propomos que este morfema seja a instanciação de um núcleo aplicativo alto.

PALAVRAS-CHAVE: Alternância de valência. Estrutura argumental. Sintaxe gerativa.

ABSTRACT: This article aims to demonstrate three different valence alternation processes in Tenetehára (Tupí-Guaraní). The first one is a process of nominal incorporation without valence decreasing. The second construction analyzed here is the antipassive voice. We show that a transitive verb can be "antipassivized" when the morpheme

* Universidade Federal de Minas Gerais (UFMG). Doutorando no Programa de Pós-Graduação em Estudos Linguísticos da Faculdade de Letras da UFMG. E-mail: ricardorrico@uol.com.br. 
$\{-\operatorname{pur}(u)\}$ is attached to it. Moreover, we claim that antipassive constructions are not restricted to ergative languages. Finally, the third phenomenon analyzed is the valence increasing, which occurs by means of the applicative morpheme $\{-\operatorname{er}(u)\}$. Based on Pylkkänen's (2002) and Vieira's $(2001,2010)$ proposal, we contend that this morpheme is the instantiation of a high applicative head.

KEYWORDS: Valence alternation. Argument structure. Generative syntax. 


\section{O EPIFENÔMENO DA ALTERNÂNCIA DE VALÊNCIA NA LÍNGUA TENETEHÁRA (TUPÍ-GUARANÍ)'}

\section{INTRODUÇÃO}

A alternância verbal é um dos temas mais discutidos na história da sintaxe. Whaley (1997), por exemplo, afirma que as línguas naturais, de modo geral, são ricas e diversas com relação aos mecanismos de aumento e diminuição de valência verbal. Assim, é neste contexto que este artigo se insere, uma vez que tem como objetivo analisar três mecanismos de mudança de valência na língua Tenetehára ${ }^{2}$. O primeiro processo examinado é a incorporação nominal, a qual, segundo Cas-

1 Gostaríamos de registrar nossos agradecimentos aos pareceristas anônimos da Revista da ANPOLL, cujas críticas contribuíram para o aperfeiçoamento deste artigo. Ao Prof. Fábio Bonfim Duarte, estendemos nossos mais sinceros agradecimentos por sua assistência. Adicionalmente, agradecemos ao Prof. Carl Harrison pelas inúmeras ponderações e lições a respeito língua Tenetehára. Esta pesquisa conta com o apoio de uma bolsa de pesquisa, financiada pela FAPEMIG (projeto número 19901) e com o apoio da Pró-Reitoria de Pesquisa da Universidade Federal de Minas Gerais (PRPq/UFMG). Parte desta investigação foi desenvolvida durante trabalho a campo realizado na terra indígena de Araribóia (nas aldeias Lagoa Quieta e Barreirinha). Gostaríamos de agradecer o importante apoio do povo indígena Tenetehára que nos ajudou no levantamento dos dados linguísticos que compõem esta pesquisa, em especial aos índios Cíntia Guajajára, Pedro Guajajára e Raimundo Guajajára.

2 A língua Tenetehára é falada no nordeste do Brasil por dois povos indígenas: os Tembé e os Guajajára. De acordo com Rodrigues (1985), essa língua pertence ao Ramo IV da família linguística Tupí-Guaraní, do Tronco Tupí. 
tro (2007), implementa a diminuição de valência, já que o objeto se incorpora ao verbo transitivo, tornando-o intransitivo. No entanto, demonstraremos, contrário a Castro (2007), que a língua em análise permite ainda a incorporação de objeto sem que haja mudança na valência do verbo. A segunda construção investigada é a voz antipassiva. Mostraremos que um verbo transitivo pode ser antipassivizado quando recebe o morfema $\{-p u r(u)\}^{3}$. A principal evidência dessa diminuição de valência é o fato de que o objeto direto de um verbo transitivo, neste contexto, passa a receber uma posposição, assim como pode ser observado em outras línguas ergativas e acusativas. Finalmente, o terceiro fenômeno analisado é o aumento de valência por meio do morfema aplicativo $\{-\operatorname{er}(u)\}^{4}$, o qual foi inicialmente analisado por Vieira (2010) com base em Pylkkänen (2002). Fundamentados nessa autora, mostraremos que esse morfema permite que um objeto seja introduzido na grade argumental de verbos intransitivos.

Este artigo está organizado em 4 seções. Na seção 1, apresentamos a formulação do problema. Na seção 2, exibimos o quadro teórico que fundamentará a proposta teórica. Na seção 3, apresentamos o sistema de marcação de Caso em Tenetehára. Por fim, na seção 4, o intuito é o de examinar dados da língua Tenetehára e relacioná-los com o quadro teórico apresentado anteriormente.

\section{FORMULAÇÃO DO PROBLEMA}

Castro (2007) propõe que os predicados transitivos em Tenetehára tornam-se intransitivos quando o objeto do verbo transitivo inicial incorpora-

3 O morfema $\{-p u r(u)\}$ é a gramaticalização do item lexical puru "gente", o qual ocorre nas incorporações nominais em contextos de diminuição de valência verbal, como no exemplo abaixo.

(i) u-puru-pytywà a'e

3-gente-ajudar ele

"(Ele) ajuda pessoas". (Castro 2010)

Nessa linha de investigação, o falante parece ter reanalisado tal vocábulo como um morfema antipassivo, na medida em que a voz antipassiva também resulta em diminuição de valência verbal, como será visto no presente artigo. Adicionalmente, Bueno (1998) afirma que o termo poro do Tupí-Guaraní-Nheengatú é um adjetivo e significa "habitante de, gente, povo, morador".

4 Seki (2000), em relação ao morfema \{ero-\}, instrui que esta unidade gramatical é um causativo comitativo. A autora analisa tal morfema na língua Kamaiurá (Tupí-Guaraní). 
-se à raiz verbal. O resultado será um verbo semanticamente transitivo, mas que c-seleciona apenas um argumento nuclear, na função de sujeito, conforme o par de exemplos abaixo:
(1a) $u-$-’u $^{2}$
tetea'u
awa
ma'e
3-comer
ASPECT
homem
coisa
"O homem comeu muita coisa"
(1b)

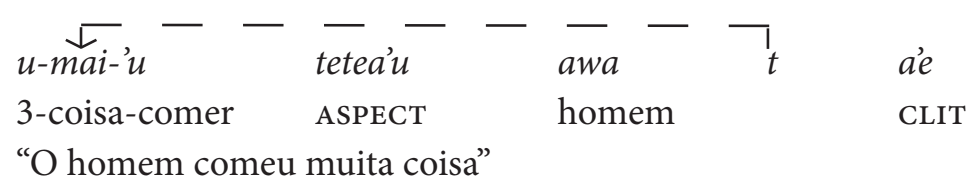

Veja que, em (1a), o verbo transitivo ' $u$ "comer" seleciona dois argumentos nucleares: o DP sujeito awa "homem" e o DP objeto ma'e "coisa”. Em (1b), por sua vez, há um processo morfossintático de incorporação do DP objeto, a saber: ma'e "coisa". Dessa forma, o argumento objeto se desloca de sua posição de base, incorporando-se à esquerda da raiz verbal, produzindo o verbo intransitivo mai-'u "comer coisa".

No entanto, novos dados coletados 5 em 2010 mostram que, no contexto de alçamento ou ascensão do possuidor ${ }^{6}$, apenas parte do objeto (a saber: o

5 Estes dados foram coletados na área indígena de Araribóia; nas Aldeias Barreirinha, Lagoa Vermelha, Vila Tarrafa, Angico Torto, Crioli, Formiga e Betel, nos meses de janeiro e fevereiro de 2010.

6 De acordo com Vieira (2010) e em consonância com Baker (1988) e Pylkkänen (2002), “as estruturas alçamento ou ascensão do possuidor (Possessor Stranding) se caracterizam pela manifestação do possuidor e do elemento possuído como dois objetos sintáticos distintos". (Vieira, 2010: 147,148). Em (ii), o dado do Chukchi, retirado de Baker (1998), exemplifica uma estrutura com alçamento de possuidor:

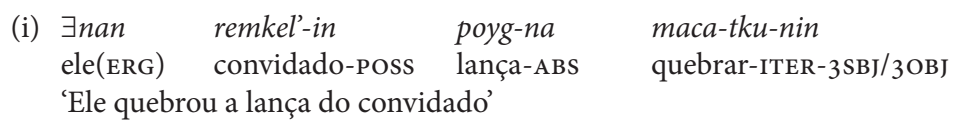

(ii) $\exists$ nan poyga-mca-tko-nen remkel'-na

ele(ERG) lança-quebrar-ITER-3SBj/3OBj convidado-ABS

'Ele quebrou a lança (para (o malefício)) do convidado

Baker (1988) 
$\mathrm{NP}$ possuído) pode se incorporar ao núcleo do $v \mathrm{P}$. O resultado desse processo não altera a estrutura transitiva inicial, como foi defendido por Castro (2007). Ou seja, nas construções de alçamento do possuidor, não existe diminuição de valência, apesar de haver incorporação.

Adicionalmente, a análise a ser apresentada neste artigo buscará evidências da existência de voz antipassiva, assim como ocorre em outras línguas ergativas e acusativas. Alguns teóricos, dentre eles Dixon (1979), Silverstein (1976) e Spencer (1991), sustentam que, de modo biunívoco, as línguas acusativas apresentam a voz Passiva, enquanto as línguas ergativas exibem a Voz antipassiva. Já Heath (1976), Postal (1977), Davies (1984), Givón (1984), Lazard (1989), Lidz (1996), Lacadema (2000), Bligth (2004), entre outros, demonstram que não só as línguas ergativas apresentam construções antipassivas, mas também as acusativas exibem estruturas que se comportam como as antipassivas.

Essa hipótese é sustentada pela análise translinguística dos fenômenos realizados pela voz antipassiva. Como poderá ser visto, esse processo parece produzir os mesmos efeitos na morfologia, na sintaxe e na semântica, tanto em línguas ergativas quanto em acusativas, tais como o inglês, o francês e o português, conforme os respectivos exemplos a seguir:
(2a) John shot the rat
(2b) John shot at the rat
BLIGHT (2004)

(3a) Elle a goûté les fraises

(3b) Elle a gồté aux fraises

HERSLUND (1997)

\footnotetext{
Note que, em (ii), o elemento possuído poygna "lança" se incorpora ao verbo maca "quebrar", alçando o possuidor remkel' "convidado" à função de objeto. Adicionalmente, quando o verbo incorpora seu objeto, o possuidor não apenas permanece fora do complexo verbal, como adquire uma relação gramatical íntegra de DP, mais especificamente, a de objeto direto. Como poderá ser percebido na subseção 2.1, essa estrutura de alçamento de possuidor também é uma estrutura de incorporação.
} 
(4a) Eu bebi o leite

(4b) Eu bebi do leite

A se confirmar que os exemplos em (b) acima sejam contextos de voz antipassiva em línguas acusativas, como afirmam Heath (1976), Postal (1977), Davies (1984), Givón (1984), Lazard (1989), Lidz (1996), Lacadema (2000), Bligth (2004), entre outros, é necessário observar que nenhuma gramática tradicional de língua portuguesa menciona a voz antipassiva ao denominar essas estruturas como voz ativa em contextos de "objeto direto preposicionado".

Postulo, dessa forma, que essas estruturas, em línguas não ergativas, são tipos de antipassivas ou, pelo menos, correspondem, em muitos pontos, a essas. Assim, o morfema $\{-p u r(u)\}$, em Tenetehára, pode ser interpretado como a realização morfológica da voz antipassiva, conforme o exemplo (6b). Além disso, é necessário que o DP sujeito das orações em que ocorre o morfema antipassivo incorpore o traço semântico "volição", por exemplo7.

$\begin{array}{lll}\text { w-exak } & \begin{array}{l}\text { Murari } \\ \text { 3-ver }\end{array} & \begin{array}{l}\text { ma'eputyr } \\ \text { flor }\end{array} \\ \text { "Murari vê a flor" } & & \\ \text { CASTRO (2010) } & & \end{array}$

$\begin{array}{lllll}\begin{array}{l}\text { i-puru-exak-wer } \\ \text { ABS-APASS-ver-DESID }\end{array} & \text { Murari } & \text { máeputyr } & \text { r-ehe a'e } \\ \text { "Murari deseja ver a flor" } & & \text { flor } & \text { C-PSP ele } \\ \text { CASTRO (2010) } & & & \end{array}$

\footnotetext{
Abreviaturas utilizadas neste trabalho abs: Caso absolutivo; acc: Caso acusativo; all: alativo; aor: aoristo; apass: morfema antipassivo; appl: morfema aplicativo; aspect: morfema aspectual; c: prefixo que marca a adjacência do complemento; clit: clítico final; com: morfema comitativo; cont: aspecto continuativo; corr: prefixo correferencial $\{\mathrm{w}-\sim \mathrm{o}-\sim \mathrm{u}-\}$; dat: dativo; desid: desiderativo; erg: Caso ergativo; fv: vogal final; fut: futuro; indic: indicativo; ins: instrumental; intr: intransitivo; iter: iterativo; np: não possuído/posse genérica; nom: Caso nominativo; noml: sufixo nominalizador; obj: objeto; pass: passado; perf: aspecto perfectivo; pl: plural; pont: aspecto pontual; poss: possessivo/genitivo; psp: posposição; prep: preposição; refl: prefixo reflexivo; sg: singular; subj: sujeito; suf: sufixo; tns: tempo; tr: transitivo; u: undergoer (paciente).

8 De acordo com Navarro (2012), "... o sufixo -wera provém do sufixo do Tupi Antigo -swer, que forma nomes deverbais que indicam propensão, inclinação ou hábito..."
} 
Em (5a), tem-se o verbo transitivo exak, o qual c-seleciona dois DPs, o sujeito Murari e o objeto ma'eputyr "flor". Em (5b), por sua vez, existe um processo morfossintático de diminuição de valência, que, como iremos assumir teoricamente na seção 3, ocorre devido à adjunção do morfema antipassivo ao predicado verbal. Adicionalmente, por meio de investigações aos informantes indígenas concluímos que o sintagma posposicional ma'eputyr rehe "(na) flor" não pode ser omitido em dados como em (5b).

Outro fenômeno interessante, que será foco de investigação neste trabalho, é a ocorrência do morfema $\{-e r(u)\}$, o qual, acompanhando Pylkkänen (2002) e Vieira (2010), mostraremos evidências de que essa unidade gramatical é a manifestação de um núcleo aplicativo alto em Tenetehára, como no exemplo (6), abaixo.

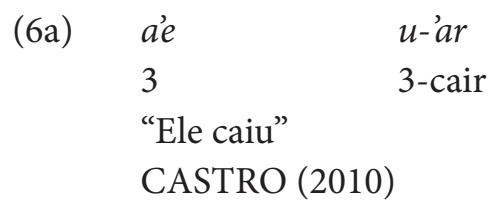
(6b) w-eru-'ar w-a'yr
3-COM-cair CORR-filho
"Ele caiu com o (próprio) filho"
CASTRO (2010)

Em (6a), o predicado inacusativo 'ar "cair" seleciona o sujeito de terceira pessoa a'e "ele", enquanto, em (6b), há um processo morfossintático de aumento no número de argumentos do predicado. Isso pode ser observado porque, em (6b), existe um DP adicional, a saber, o DP wa'yr "filho". Esse aumento de valência parece estar conectado com o fato de que, em (6b), um morfema aplicativo $\{-e r(u)\}$ é adjungido ao verbo 'ar "cair", tornando-o transitivo. Dessa forma, esse morfema introduz um objeto aplicativo com a propriedade semântica de comitativo ${ }^{9}$. Na próxima seção, apresento o quadro teórico que fundamentará esse trabalho.

9 O morfema $\{-\operatorname{er}(u)\}$ é denominado morfema causativo-comitativo na tradição descritiva de línguas indígenas brasileiras. 


\section{QUADRO TEÓRICO}

Nesta seção, faremos uma breve revisão bibliográfica a respeito dos assuntos que serão tratados no presente estudo. Para o fenômeno da incorporação, sintetizaremos a proposta de Baker (1988) e Hale \& Kayser (1993, 2002). Em relação aos sistemas de Caso nominativo e ergativo faremos alusão principalmente a Dixon (1979). Sobre a introdução de objetos com a função de comitativo, utilizaremos a tipologia de aplicativos de Pylkkänen (2002). Por fim, acerca das construções de voz antipassiva, faremos referência aos trabalhos de Lazard (1989), Lacadema (2000), Bligth (2004), entre outros.

\subsection{Incorporação}

Segundo Baker (1988), em algumas línguas ergativas, há um contexto em que, quando o objeto de verbos transitivos se incorpora no núcleo do predicado, a codificação do objeto no verbo é modificada, uma vez que houve mudança de funções gramaticais dos elementos, conforme os exemplos do Chukchi retirados de Baker (1988).

$\begin{array}{llll}\exists \text { nan } \quad \text { remkEl-in } & \text { pojg-En } & \text { mcEtku-nin } \\ \text { 3PL.ERG } & \text { convidado-POss } & \text { lança-ABs } & \text { quebrar-3SG.SUBJ/3SG.OBJ } \\ \text { "Ele quebrou a lança do convidado" } & \end{array}$

$\begin{array}{lll}\exists \text { nan } & \text { pojgE-mcatko-nen } & \text { remkEl-En } \\ \text { 3PL.ERG lança-quebrar-3SG.SUBJ/3SG.OBJ } & \text { convidado-ABS } \\ \text { "Ele quebrou a lança (para (o malefício)) do convidado" } \\ \text { BAKER (1988) }\end{array}$

Pode-se notar que, em (7a), o predicado é uma estrutura transitiva sem incorporação, que possui um objeto direto modificado por um possuído NP, marcado com um sufixo possessivo. Quando o verbo incorpora seu objeto, o possuidor não apenas permanece fora do complexo verbal, mas adquire uma relação gramatical total do NP - isto é, de objeto direto - e é marcado com Caso absolutivo, como mostrado em (7b). 
Conforme Baker (1988), a incorporação é um fenômeno sintático, em que um núcleo é movido de sua posição de base para uma posição mais alta. Adicionalmente, tal movimento deve satisfazer o Princípio da Categoria Vazia (Empty Category Principle - ECP). Desta forma, o elemento movido precisa deixar um traço na posição em que é gerado. Esse traço deve ser c-comandado pelo objeto movido. Além disso, de acordo com Baker (1988), na operação sintática incorporação, deve haver uma relação biunívoca entre a estrutura semântica e a estrutura sintática. Isso significa que a Hipótese da Uniformidade de Atribuição Theta (Uniformity of Theta-Assignment Hyphotesis - UTAH) deve ser satisfeita. Assim sendo, quando os itens são inseridos na derivação, deve haver um mapeamento um a um, a saber: a relação entre a estrutura temática e a sintática deve ser preservada. Na próxima subseção, o intuito é discorrer brevemente a respeito dos sistemas de Caso, os quais foram propostos por Dixon (1979).

\subsection{Sistemas de caso nominativo e ergativo}

Translinguisticamente, existe uma distinção em sentenças que envolvem um verbo monoargumental e aquelas que abrangem predicados verbais que selecionam dois ou mais argumentos nucleares. De acordo com Dixon (1979), há a proposição de que as línguas operam em termos de três relações primordiais, a saber: (i) $\mathrm{S}$ - sujeito intransitivo; (ii) A - sujeito transitivo; e (iii) $\mathrm{O}$ - objeto transitivo.

Assim sendo, nas línguas em que atua o sistema nominativo-acusativo, (S) e (A) são tratados gramaticalmente da mesma forma, como pode ser visto nos exemplos (8) do Latim retirados de Duarte (2007). Nesses dados, o morfema de Caso nominativo $\{-u s\}$ ocorre em DPs que figuram nas duas posições de sujeito, tanto em (A) quanto em (S).

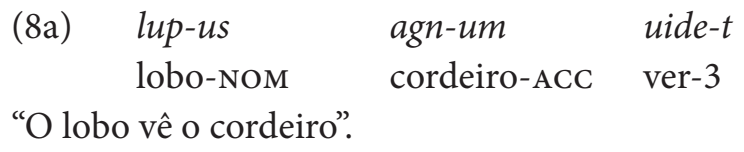


(8b)

$$
\begin{array}{ll}
\text { lup-us } & \text { veni-t } \\
\text { lobo-Nom } & \text { vir-3 } \\
\text { "O lobo vem". } &
\end{array}
$$

Já em línguas do tipo ergativo-absolutivo, (S) e (O) recebem, geralmente, uma marca gramatical idêntica, como nos dados abaixo do kuikuro retirados de Franchetto (1990). As relações (A) e (O) recebem o prefixo de Caso absolutivo $\{\varnothing-\}$
(9a) karaihá
ø-kacun-tárâ
branco
ABS-trabalhar-CONT
"O branco está trabalhando".
(9b)
tâ-murú
$\emptyset$-ikaín-jâ
itaó-heke
REFL-filho
ABS-levantar-PONT
mulher-ERG
"A mulher levantou seu (próprio) filho".

Nessa linha de investigação, é possível delinear essas relações, de acordo com o quadro a seguir:

\section{Quadro 1}

Sistemas de Caso e codificação argumental

Sistema Nominativo

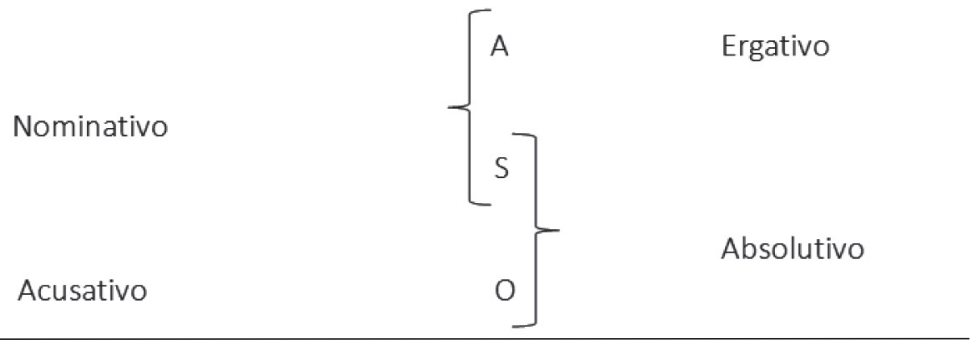

Sistema Ergativo 
Além das situações já mostradas, muitas línguas apresentam, adicionalmente, uma combinação entre o sistema nominativo-acusativo e o ergativo-absolutivo. Neste contexto, ocorre um sistema cindido na codificação argumental (A), (S) e (O). Essa cisão é, via de regra, intitulada como Split-S System. Vários fatores gramaticais são responsáveis por engatilhar tal combinação de sistemas, como o papel temático atribuído aos argumentos nucleares na posição de sujeito $(\mathrm{A}) /(\mathrm{S})$ e $(\mathrm{O})$, a natureza semântica do verbo e outros. O sistema cindido será observado na seção 3, em que exibiremos o sistema de marcação de Caso em Tenetehára. Para detalhes a respeito da estrutura argumental da língua Tenetehára, remeto o leitor aos trabalhos de Harrison (1986), Duarte (2012a, 2012b) e Camargos (2013).

Na próxima subseção, retomamos algumas propostas teóricas relacionadas ao fenômeno da voz antipassiva.

\subsection{Voz antipassiva}

Acompanhando Silverstein ${ }^{10}$ (1972), Polinsky (2005) e outros, voz antipassiva é uma construção derivada destrantivizada, relacionada a uma construção transitiva correspondente cujo predicado é o mesmo item lexical. Desta forma, a voz antipassiva faz um verbo, originalmente transitivo, tornar-se intransitivo. Em uma construção transitiva, o DP objeto direto geralmente é o paciente. Já em uma construção na voz antipassiva, esse DP objeto pode tanto ser suprimido (permanecer implícito), de acordo com Polinsk (2005), ou realizado como um complemento oblíquo, segundo Aldridge (2012).

O termo antipassiva foi cunhado por Silverstein (1972) com a finalidade de indicar que essa construção é a imagem espelhada da voz passiva, da seguinte forma: (i) na voz passiva, o DP suprimido ou demovido é o argumento externo, cuja tendência é ser o agente da construção; (ii) na voz antipassiva, o DP suprimido ou demovido é o argumento interno, o qual ten-

\footnotetext{
${ }^{10}$ A reunião de autores teoricamente localizados em posições distintas é justificada pelo fato de que se deve a uma maioria de trabalhos descritivos o próprio aumento da base empírica sobre fenômenos das línguas no mundo. Assim sendo, é exatamente sobre essa base empírica proveniente de descrições linguísticas que os linguistas formais, entre os quais os gerativistas, apoiam comumente suas reflexões, formalizações, explicações.
} 
de a ser o paciente. Tipologicamente, pode-se verificar, ainda na literatura linguística, as seguintes possibilidades de estruturas antipassivas, a saber: (i) demoção do objeto por meio de adposições; (ii) incorporação do objeto; (iii) redução a zero ${ }^{11}$; e (iv) pivô sintático ${ }^{12}$.

A fim de evidenciar a voz antipassiva em contexto de demoção de objeto por meio de adposição, arrolo os seguintes dados do iucateque, em que se pode observar uma construção na voz ativa e uma na antipassiva, respectivamente:

\begin{tabular}{|c|c|c|c|c|}
\hline \multirow[t]{3}{*}{$(10 \mathrm{a})$} & $\begin{array}{l}\text { màalob' } \\
\text { bem }\end{array}$ & $\begin{array}{l}\text { 'a-tan-ik } \\
\text { 2sG-falar-PERF }\end{array}$ & \multicolumn{2}{|c|}{ màayah } \\
\hline & \multicolumn{4}{|c|}{ "Você fala maia bem" } \\
\hline & \multicolumn{4}{|c|}{ BLIGHT (2004) } \\
\hline \multirow[t]{4}{*}{$(10 b)$} & mäalob’ & 'a-t'àan & 'its & màayah \\
\hline & bem & 2SG-falar.APASS & PREP & Maia \\
\hline & \multicolumn{4}{|c|}{ "Você fala maia bem" } \\
\hline & BLIGHT & 2004) & & \\
\hline
\end{tabular}

No dado (10a) do iucateque, tem-se o verbo transitivo tan "falar", o qual seleciona dois argumentos nucleares: um sujeito de segunda pessoa representado pelo prefixo \{'a-\} e o argumento interno màayah "Maia". Já em (10b), pode-se observar um processo morfossintático de diminuição de valência verbal, que descrevo da seguinte maneira: o morfema antipassivo é adjungido ao verbo tan "falar", fazendo-o evolver para t’àan "falar". Esse predicado passa a selecionar apenas o sujeito de segunda pessoa $\{$ ' $a$ - $\}$, uma vez que o DP objeto da sentença original màayah "Maia" é demovido de sua função de

${ }^{11}$ Foley \& Van Valin (1985) distinguem dois principais tipos de antipassivas: antipassivas figura e antipassivas fundo (foregrounding e backgrounding). As antipassivas figura são as que ocorrem em línguas com o sistema de pivô sintático. As antipassivas fundo, por sua vez, são as estruturas dos tipos demoção do objeto por meio de adposições, incorporação do objeto e redução a zero.

${ }^{12}$ O pivô sintático, de acordo com De Vries (2002), estabelece que a oração principal e a encaixada estejam diretamente conectadas. Além disso, essa conexão entre as duas orações é realizada tanto no nível sintático quanto no semântico. 
objeto passando a ser introduzido pela preposição 'itS. Ressalta-se, em (10b), a ausência do afixo de aspecto gramatical perfectivo $\{-i k\}$. Essa inexistência afixal parece apontar para o fato de que o aspecto gramatical, muitas das vezes, é sensível à alternância ativa/antipassiva, como previsto por Polinsk (2005). O mesmo fenômeno de demoção de objeto por meio de adposição pode ser observado no inglês, conforme os exemplos abaixo:

(11a) John shot the rat
"John (atirou e) matou o rato"

(11b) John shot at the rat

"John atirou no rato"

Em (11a), o predicado transitivo shot atirar seleciona dois argumentos nucleares, o DP sujeito John e o DP objeto rat "rato". No exemplo (11b), por sua vez, ocorre um morfema antipassivo nulo $\{\varnothing\}^{13}$. Essa unidade gramatical tem como função demover o DP rat "rato", uma vez que esse último passa a oblíquo. O resultado dessa operação de decréscimo de valência é que o verbo transitivo shot "atirar" é reanalisado como monoargumental. Ressalta-se que, em (11a), por um lado, o DP objeto rat "rato" é totalmente afetado pela ação expressa pelo predicado verbal; por outro lado, em (11b), o DP rat "rato", agora encabeçado pela preposição at "em", não é necessariamente afetado. Tal incerteza de afetação parece confirmar que o emprego ora da voz ativa ora da antipassiva, produz, frequentemente, alternância no aspecto verbal, como fora visto também em (10).

Portanto, a voz antipassiva, quando demove DPs objetos por meio de adposições, diminui a valência verbal do predicado transitivo em que ocorre, o qual evolve a intransitivo. Nessa linha de investigação, a adposição presen-

${ }^{13}$ Uma vez que estamos buscando mais evidências para a existência de voz antipassiva tanto em línguas ergativas quanto em acusativas, essas últimas confirmadas por Heath (1976), Postal (1977), Davies (1984), Givón (1984), Lazard (1989), Lidz (1996), Lacadema (2000), Bligth (2004), entre outros; nossa solução temporária é a de que o morfema antipassivo é $\{\varnothing\}$ em muitas línguas. Essa afirmação encontra respaldo uma vez que, translinguisticamente, tanto os morfemas antipassivos plenos quanto o nulo produzem, via de regra, os mesmos efeitos sintáticos e semânticos. Trabalhos futuros poderão corroborar tal afirmação. 
te na estrutura é quem seleciona o argumento agora nucleado por um PP, sendo, por isso, uma adposição lexical ${ }^{14}$. Assim, o antigo DP objeto argumento do predicado transitivo original passa a ser argumento da adposição da oração derivada.

Em termos teóricos, a voz antipassiva, atuando em contextos de incorporação de objeto, é um fenômeno sintático de diminuição de valência. Um DP objeto de um verbo transitivo é movido de sua posição de base para dentro da raiz verbal. Esse fenômeno resulta no fato de que um verbo transitivo é reanalisado como intransitivo. Como exemplo da antipassiva em contexto de incorporação de objeto, arrolo o seguinte dado da língua Tiwa do sul, retirados de Allen (1988):

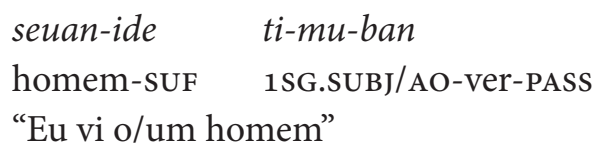

seuan-ide ti-mu-ban

homem-SUF 1SG.SUBJ/AO-ver-PASS

"Eu vi o/um homem"

ALLEN (1988)

(12b) ti-seuan-mu-ban

1SG.SUBJ/AO-homem-ver-PASS

"Eu vi o/um homem"

ALLEN (1988)

Conforme mostra o exemplo (12a), o predicado transitivo ban "ver" seleciona o sujeito de primeira pessoa representado pelo prefixo $\{-t i\}$ e o DP objeto seuanide "homem". Por sua vez, em (12b), há um processo de incorporação do DP objeto seuanidi "homem”. Dessa forma, no dado (12a), o DP objeto seuanidi "homem" aparece como um item lexical independente e com o morfema de concordância de Caso objetivo, o qual é atribuído pelo

\footnotetext{
${ }^{14}$ As adposições (preposições e posposições) lexicais, também denominadas predicadoras, selecionam argumentos. Já as adposições funcionais não os selecionam. Um exemplo de preposição funcional é "de" em "Joanina gosta de leite". Observem que o PP "de leite" é selecionado pelo verbo "gosta", ou seja, tanto a preposição quanto o nome são selecionados pelo verbo. Um exemplo de preposição lexical é "de" em "Joanina correu de tênis". Observe que o DP "tênis" é selecionado pela preposição lexical (predicadora) "de" e não pelo verbo "correr", o qual é intransitivo.
} 
predicado ban "ver". Já em (12b), o DP objeto seuani "homem" é realizado dentro do complexo verbal e sem a marcação morfológica de Caso objetivo \{-ide\}, pois é um DP nu. Situação que resulta na diminuição de valência do verbo transitivo ban "ver", o qual passa a selecionar apenas o sujeito de primeira pessoa, representado pelo prefixo $\{-t i\}$.

Nas ocorrências em que a voz antipassiva reduz o objeto a zero, ocorre decréscimo na valência do predicado transitivo em que o fenômeno se realiza. Ou seja, existe uma construção original transitiva correspondente e uma derivada antipassivizada e, por causa disso, intransitiva. Com o intuito de apresentar um dado em que a antipassiva suprime o DP objeto, relaciono o seguinte exemplo do inglês:

(13a) Speed kills people.

"Velocidade mata pessoas"

(13b) Speed kills!

"Velocidade mata!"

Em (13a), o predicado transitivo kills "mata" requer dois argumentos nucleares, o DP sujeito speed "velocidade" e o DP objeto people "pessoas". No exemplo (13b), por sua vez, o predicado recebe o morfema antipassivo $\{\varnothing\}$ cuja função é a diminuição de valência. Assim sendo, esse verbo transitivo kills "mata" passa de transitivo para intransitivo, selecionando apenas o DP sujeito speed "velocidade". Adicionalmente, não se deve confundir a estrutura antipassiva (13b) com a segunda oração em (14).

A velocidade mata muitas pessoas. A violência também mata.

Em (14), o verbo transitivo "matar" da primeira oração seleciona o DP objeto "muitas pessoas". Adicionalmente, no segundo período, o objeto omitido do verbo "matar" é inferido contextualmente. Situação sintática não compartilhada com (13b). Ou seja, na construção em que a antipassiva suprime o objeto, esse último não pode ser inferido pelo contexto. 
O pivô sintático, em períodos com coordenação, por exemplo, é simplesmente um mecanismo que faz com que, na segunda oração, o argumento omitido (pro $)^{15}$ seja o mesmo que o argumento explícito da primeira principal. Nessa linha de investigação, o pivô sintático é um constituinte partilhado por duas orações em coordenação ou subordinação ${ }^{16}$. Mesmo que nessa última o argumento não esteja explícito, ele pode ser recuperado. De forma geral, um argumento que se encontra numa oração é idêntico ao que se encontra em outra, permitindo, assim, estabelecer equivalência entre eles. Observe o seguinte exemplo:

(15) Eu disparei nos cervos e matei-os.

No exemplo (15), o DP explícito “Eu”, da oração matriz, exerce a mesma função sintático-semântica do argumento sujeito (pro) omitido na oração encaixada. Em várias línguas ergativas que têm um sistema de pivô sintático, existe a exigência de que o argumento que recebe Caso absolutivo deve ser o "controlador" e o "alvo" de uma anáfora zero em sentenças complexas. Dessa forma, tanto o DP que correferencia um DP omitido quanto o próprio DP suprimido devem receber Caso absolutivo. Nesse contexto, o uso da voz antipassiva será obrigatório se, por exemplo, um sujeito intransitivo (com Caso absolutivo), na primeira oração, correferenciar um sujeito transitivo (com Caso ergativo) em uma segunda oração. Nesse caso, a ocorrência da antipassiva na segunda oração permite ao DP sujeito dessa oração receber Caso absolutivo ao invés de Caso ergativo. Concluindo, não só o DP sujeito da primeira oração, mas também o DP sujeito da segunda oração receberão o mesmo Caso abstrato, a saber: o absolutivo. Observe o seguinte exemplo da língua dyirbal abaixo.

${ }^{15}$ Sujeitos nulos, em orações finitas e não finitas, são tratados, pela sintaxe gerativa, como pro e $P R O$, respectivamente.

${ }^{16}$ Na realidade, o pivô sintático ocorre em orações complexas (subordinadas e coordenadas). Neste artigo, optamos por exibir o pivô sintático apenas em períodos em coordenação. Essa escolha deve-se ao fato de que esse assunto não é central na presente análise. Para mais detalhes a respeito do pivô sintático, remeto o leitor ao trabalho de Foley \& Van Va$\operatorname{lin}(1985)$. 


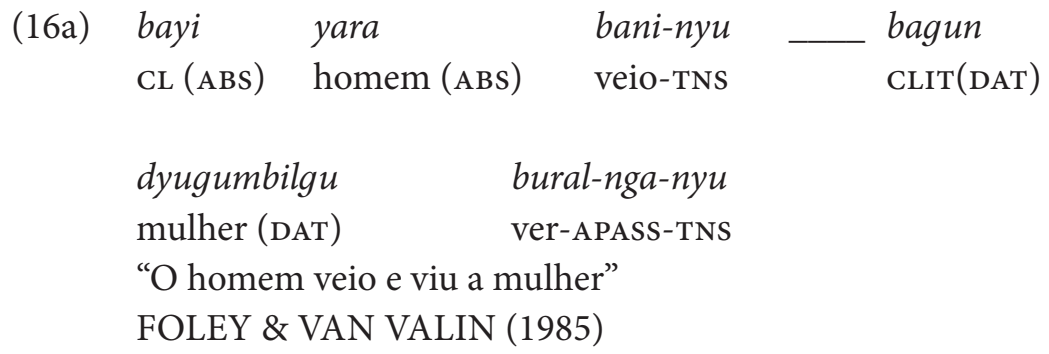

Em (16a), o verbo transitivo da primeira oração seleciona o DP yara "homem", o qual, nesse contexto, recebe Caso absolutivo. Já ao predicado da segunda oração bural "ver", também transitivo, é adjungido o morfema antipassivo $\{-n g a-\}$, que tem a função de demover o DP objeto dyugumbil "mulher", o qual passa a oblíquo, recebendo o afixo $\{-g u\}$ e sendo realizado como dyugumbilgu "mulher". Como dyugumbilgu "mulher" é agora oblíquo, o DP sujeito omitido da segunda oração, em (16a), só pode receber o mesmo Caso do sujeito da primeira sentença, a saber, o acusativo. Isso resulta, em dyirbal, numa construção sintática bem formada. Caso o predicado da segunda oração bural "ver" não recebesse o morfema antipassivo, ter-se-ia a seguinte construção agramatical.

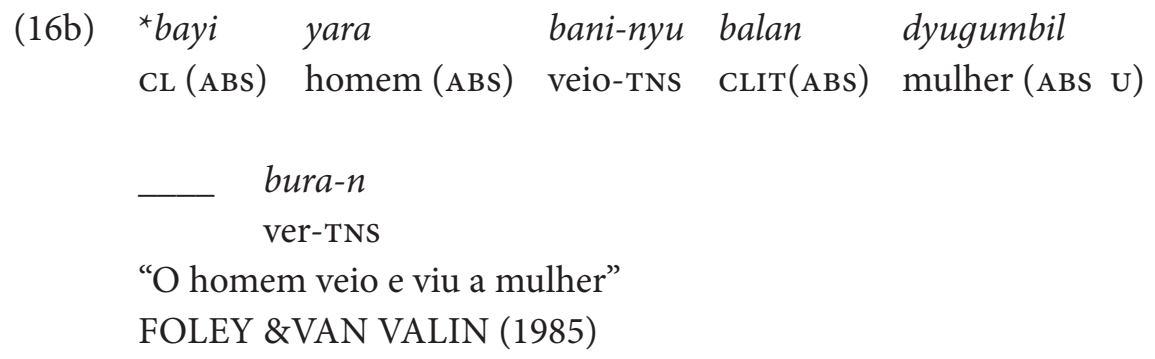

No exemplo (16b), o predicado intransitivo baninyu "veio", da primeira oração, seleciona o DP yara "homem", o qual, nesse contexto, recebe Caso absolutivo. Já o predicado da segunda oração bural "ver" é transitivo e c-seleciona dois argumentos nucleares, o DP sujeito (que recebe Caso ergativo) recuperável pela inferência pragmática, yara "homem" e o DP objeto dyugumbil "mulher", o qual recebe Caso absolutivo, situação sintática 
agramatical em dyirbal. Essa agramaticalidade está conectada com o fato de que, como já dito, tanto ao DP, na primeira oração, como ao DP omitido na segunda oração deve ser atribuído o mesmo Caso abstrato, a saber, o absolutivo.

Com o propósito de deixar evidente que o aspecto verbal é sensível à alternância ativa/antipassiva, tem-se o exemplo da língua Chukchi a seguir:
(17a) etleg-e
keyng-en
penre-nen
pai-ERG
urso-ABS
atacar-3SG.3SG.AOR
"O pai atacou o urso"
PALMER (1994)
(17b) etleg-en penre-tko-g'e kayng-ete
pai-ABS atacar-APASS-3SG.AOR urso-DAT
"O pai correu em direção ao urso (com a intenção de atacá-lo)" PALMER (1994)

Em (17a), o verbo transitivo penre "atacar" atribui o Caso ergativo ao DP sujeito etlege "pai" e o Caso absolutivo ao DP objeto penrenen "urso". Já em (17b), esse predicado recebe o morfema antipassivo $\{-t k o-\}$, cuja função é demover o DP objeto da estrutura transitiva inicial. Em (17b), o DP etlegen "pai" recebe Caso absolutivo, enquanto que o DP objeto da estrutura transitiva inicial é demovido a oblíquo (dativo), sendo realizado como penretkog’e "urso". No final do processo, o verbo transitivo penre "atacar" é reanalisado como intransitivo. Em respeito à relação aspectual de telicidade, no exemplo (17b), existe uma sensação em que o evento é menos completo do que em relação a (17a), o que pode ser notado pelas traduções de (17).

Alguns autores, tais como Silverstein (1976), Dixon (1979), Spencer (1991), entre outros, argumentam que existe um mapeamento biunívoco da seguinte maneira: as línguas acusativas apresentam a voz passiva, enquanto as línguas ergativas exibem a voz antipassiva. Já, trabalhos como os de Heath (1976), Postal (1977), Davies (1984), Givón (1984), Lazard (1989), Lidz (1996), Lacadema (2000), Bligth (2004), entre outros, demonstram que não só as línguas ergativas oferecem estruturas antipassivas, mas também 
as acusativas exibem uma construção sintática que parece corresponder às antipassivas. Essa hipótese é sustentada pela análise translinguística dos fenômenos realizados pela voz antipassiva.

O propósito deste trabalho é argumentar a favor da hipótese de que, nos casos em que há um processo de intransitivização do predicado e demoção do objeto direto para a posição de adjunto (o que a tradição gramatical denomina como "objeto direto preposicionado"), tem-se um contexto específico de voz antipassiva. Assim, o que os dados mostrarão é que nas línguas acusativas também ocorre essa construção.

Assumimos, juntamente com Herslund (1997), Blight (2004), Polinsk (2005) e outros, que, apesar do fato de as línguas ergativas terem uma tendência maior a fazer uso da voz antipassiva do que as acusativas, o fenômeno não é exclusivo das línguas ergativas. O que parece existir é uma disposição de ocorrência que pode ser traduzida por dois termos quase que intercambiáveis: produtividade de antipassivas, conforme Polinsk (2005), e níveis de gramaticalização de antipassivas, de acordo com Herslund (1997). Esse último autor motiva a existência de uma gradação com respeito à ocorrência de antipassivas nas línguas do mundo.

Dependendo da alternância de voz ativa e antipassiva, dir-se-á que existe o seguinte: (i) alternância totalmente gramaticalizada: todos os verbos transitivos, em uma língua $X$, aceitam a alternância voz ativa/antipassiva, como por exemplo o groenlandês ocidental; (ii) alternância parcialmente gramaticalizada: a alternância ativa/antipassiva, embora expandida, comum, frequente e aparentemente se propagando por uma língua $\mathrm{X}$, não ocorre com todos os verbos da classe dos transitivos, como no dinamarquês; e (iii) alternância determinada lexicalmente: não existe sistematicidade na escolha da alternância. A determinação é lexical e não gramatical. Ou seja, a ocorrência de voz antipassiva, nessas línguas, é restrita a poucos predicados transitivos, por exemplo, o português. Como modelo de alternância totalmente gramaticalizada, analisamos os seguintes dados da língua groenlandesa do oeste, retirados de Herslund (1997):

$\begin{array}{llll}\text { (18a) Jaakup } & \text { illu } & \text { sanavaa } \\ \text { Jacob-ERG } & \text { casa(ABs) } & \text { estar.construindo-TR.INDIC-3SG.ERG/3SG.ABS } \\ \text { "Jacó está/estava construindo a casa" }\end{array}$



(18b) Jaaku illu-mik sanavuq
Jacó(ABS) casa-INS estar.construindo-APASS-INTR.INDIC-3SG.ABS "Jacó está/estava construindo a casa"

As principais diferenças entre as versões transitiva e antipassiva são: no exemplo (18a), ao DP agente é atribuído o Caso ergativo, já em (18b), o DP agente recebe Caso absolutivo. Além disso, em (18a), o DP paciente recebe Caso absolutivo, por seu turno, em (18b), esse mesmo DP paciente é demovido a oblíquo (instrumental). Finalmente, em (18a), o verbo é flexionado transitivamente e concorda tanto com o DP sujeito quanto com o DP objeto, contrariamente, em (18b), o verbo concorda apenas com o sujeito da sentença.

Nessa linha de investigação, em (18b), é adjungido ao verbo o morfema antipassivo $\{\varnothing\}$, o qual tem a função de diminuir a valência do verbo transitivo original. Ao final das contas, em (18b), o verbo, agora destransitivizado, passa a concordar apenas com o agente da sentença. A fim de fornecer um exemplo de alternância parcialmente gramaticalizada, tem-se o seguinte exemplo do dinamarquês.

\begin{tabular}{|c|c|c|c|c|c|}
\hline$(19 a)$ & $\begin{array}{l}\text { Jakob } \\
\text { Jacó }\end{array}$ & $\begin{array}{l}\text { byggede } \\
\text { construiu }\end{array}$ & $\begin{array}{l}\text { et } \\
\text { uma }\end{array}$ & $\begin{array}{l}\text { hus } \\
\text { casa }\end{array}$ & \\
\hline & $\begin{array}{l}\text { "Jacó c } \\
\text { HERS }\end{array}$ & $\begin{array}{l}\text { struiu uma } \\
\text { ND (1997) }\end{array}$ & & & \\
\hline$(19 b)$ & Jakob & byggede & & et & hus \\
\hline & $\begin{array}{l}\text { "Jacó } \\
\text { HERS }\end{array}$ & $\begin{array}{l}\text { struiu uma } \\
\text { ND (1997) }\end{array}$ & a" & & \\
\hline
\end{tabular}

Por um lado, em (19a), o verbo transitivo byggede "construiu" seleciona o DP sujeito Jakob e o DP objeto et hus "uma casa"; por outro lado, em (19b), o verbo byggede "construiu" é destransitivizado. Ou seja, em (19b), um morfema antipassivo $\{\varnothing\}$ é associado ao predicado byggede "construiu", o qual passa a selecionar um único argumento, a saber, o DP Jakob. Adicionalmente, o DP et 
hus "uma casa" passa a ser, em (19b), um argumento não do predicado byggede "construiu”, mas sim da preposição lexical (=predicadora) på. Na língua dinamarquesa, exemplos como (19b) são produtivos, mas não ocorrem com todos os verbos transitivos. Por isso, Herslund (1997) considera que, nessa língua, a alternância ativa/antipassiva é parcialmente gramaticalizada. Já em línguas em que a alternância entre a construção transitiva e a preposicionada ocorre em uma escala muito menor, tem-se a alternância determinada lexicalmente. Essa situação sintática parece ocorrer principalmente nas línguas acusativas, como pode ser notado no exemplo do francês abaixo:
(20a) elle a
goûté
les fraises
ela tem
experimentado os
"Ela experimentou os morangos"

$\begin{array}{lllll}\text { (20b) elle a goûté } & \text { aux } & \text { fraises } \\ \text { Ela tem experimentado } & \text { PREP } & \text { morangos } \\ \text { "Ela experimentou os morangos" } & & \end{array}$

Em (20a), o predicado transitivo a goûté "experimentou" seleciona o DP sujeito Elle "Ela" e o DP objeto les fraises “os morangos". Já em (20b), há processo morfossintático de diminuição de valência. Assim sendo, em (20b), um morfema antipassivo $\{\varnothing\}$, cuja função é diminuir a valência do verbo, pode ser associado a esse último. Dessa forma, o predicado transitivo da construção inicial passa a ter apenas um argumento nuclear, a saber, o DP elle "ela”. Adicionalmente, propomos que o DP fraises "morangos", em (20b), é argumento nuclear da preposição predicadora (lexical) aux. Outro exemplo de antipassiva determinada lexicalmente pode ser analisado nos seguintes exemplos do português:

(21a) Geraldo bebeu leite

(21b) Geraldo bebeu do leite

Em (21a), o verbo transitivo "bebeu" c-seleciona dois DPs, o sujeito "Geraldo" e o objeto "leite”. Já em (21b), ocorre um morfema antipassivo $\{\varnothing\}$, 
que tem a função de diminuir o número de argumentos de um predicado, é adjungido ao verbo transitivo "bebeu", o qual passa a monoargumental. Ao fim do fenômeno sintático, o verbo "bebeu" seleciona apenas o DP sujeito "Geraldo". Além disso, sugiro que, em (22b), o DP "leite" é argumento da preposição predicadora "de".

Uma vez apresentados os processos que alteram a valência verbal por meio da demoção do objeto, discutiremos, na próxima subseção, os processos que, ao introduzir um novo argumento na estrutura, aumentam a valência verbal da sentença. Para analisar essas construções tomaremos como base a tipologia proposta em Pylkkänen (2002).

\subsection{Núcleos Aplicativos}

Descritivamente, morfemas aplicativos têm a função de mudar a valência de predicados verbais, introduzindo, assim, um argumento com a função de objeto nas estruturas em que ocorrem. Paralelamente, objeto aplicativo é um argumento inserido na estrutura de um verbo quando recebe a morfologia de núcleo aplicativo. Sendo assim, os núcleos aplicativos podem: (i) promover sintagmas oblíquos ao estatuto de objetos; (ii) tornar verbos intransitivos em transitivos; e (iii) transformar verbos transitivos em bitransitivos. Observe os seguintes exemplos da língua Kinyarwanda, retirados de Pylkkänen (2002):

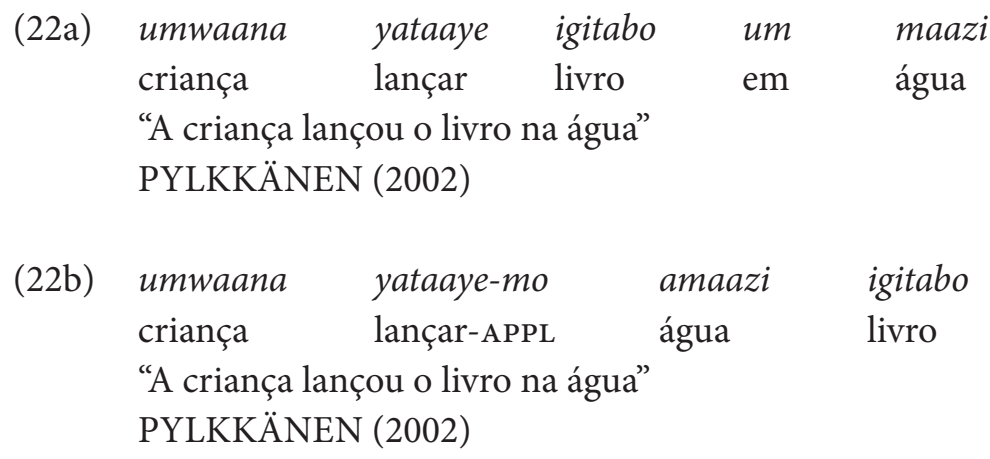


Em (22a), temos o verbo yataaye "lançar", o qual seleciona o sujeito umwaana "criança" e dois DPs, a saber: o objeto direto igitabo "livro" e o objeto indireto um maazi "na água". Em (22b), por sua vez, existe um processo morfossintático em que o morfema aplicativo $\{-m o\}$ é adjungido ao verbo yataaye "lançar". A consequência desse fenômeno morfossintático é que a sentença passa a ter dois objetos diretos, uma vez que em (22b) a preposição um "em" não figura e o DP amaazi "água" torna-se um objeto aplicado.

Para Pylkkänen (2002), os objetos aplicados podem ter variados papéis semânticos, tais como: benefativo, instrumento, locativo, comitativo, malefativo, fonte, alvo, entre outros. Conforme a autora, há uma aparente semelhança semântica e sintática nas construções aplicativas intra e interlinguisticamente. No entanto, essas semelhanças são superficiais. Diante disso, a partir do quadro da Morfologia Distribuída de Marantz (1997), Pylkkänen (2002) motiva uma tipologia dos núcleos funcionais aplicativos, a saber: aplicativo baixo e aplicativo alto. O primeiro é projetado abaixo do VP, conforme a estrutura configuracional em (23).

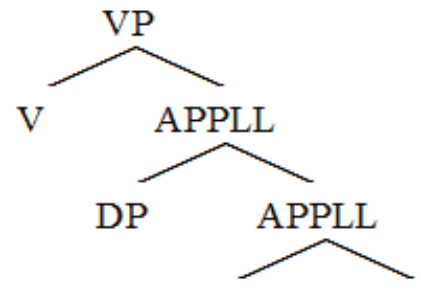

APPLL DP

Semanticamente, o núcleo aplicativo baixo, exerce a função de estabelecer uma relação de transferência de posse entre os dois objetos. Conforme o diagnóstico sintático de Pylkkänen (2002), só ocorre morfologia de aplicativo baixo em construções transitivas como nos exemplos de luganda e finlandês a seguir:

$\begin{array}{llll}\text { Mukasa ya-som-e-dde } & \text { Katonga } & \text { ekitabo } \\ \text { Mukasa } & \text { 3sG.PASs-ler-APPL-PASs } & \text { Katonga } & \text { livro } \\ \text { "Mukasa leu o livro para Katonga" } & & \\ \text { LKKÄNEN (2002) } & & \end{array}$


No exemplo da língua luganda, em (24), o verbo transitivo som "ler" seleciona o sujeito Mukasa e o objeto ekitabo "livro". Adicionalmente, esse verbo recebe o morfema aplicativo baixo $\{-e-\}$, cuja função é introduzir o argumento Katonga. Ao final desse processo morfossintático, o verbo som "ler" passa de transitivo a bitransitivo. Nesse exemplo, o objeto aplicativo Katonga recebe papel temático de beneficiário atribuído pelo núcleo aplicativo baixo. Além disso, existe uma relação de transferência de posse entre os dois objetos. Veja abaixo um exemplo do finlandês.

$\begin{array}{llll}\text { Liisa } \quad \text { kirjoitti } & \text { Mati-lle } & \text { kirjee-n } \\ \text { Liisa.NOM } & \text { escreveu } & \text { Matti-ALL } & \text { carta-ACC } \\ \text { "Liisa wrote } & \text { Matti a letter" } & \\ \text { PYLKKÄNEN (2002) } & & \end{array}$

No dado (25), tem-se o verbo transitivo kirjoitti “escreveu", que introduz o sujeito Liisa e objeto kirjeen "carta”. Além disso, ocorre um morfema aplicativo nulo $\{\varnothing\}$, o qual tem a função de selecionar o argumento aplicativo Matille. Assim, o predicado transitivo kirjoitti "escreveu" torna-se bitransitivo. Ressalta-se que o objeto aplicativo Matille recebe papel semântico de beneficiário pelo núcleo aplicativo baixo, como também existe uma relação de posse entre os dois DPs objetos. O aplicativo alto, por sua vez, é projetado acima de VP, conforme (26).

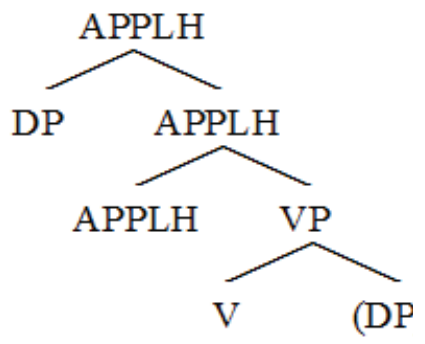

Semanticamente, o núcleo aplicativo alto tem a função de introduzir um objeto aplicativo com funções semânticas diversas (comitativo, beneficiário, fonte, alvo, locativo, instrumento, dentre outros). Segundo Pylkkänen 
(2002), sintaticamente, o aplicativo alto pode afixar-se a verbos inacusativos e inergativos, conforme o exemplo abaixo da língua venda:

$\begin{array}{lll}\text { Mukasa } \quad \text { o-amb-el-a } & \text { Katonga } \\ \text { Mukasa } & \text { 3sg.PAss-falar-APPL-FV } & \text { Katonga } \\ \text { "Mukasa falou para Katonga" } & \end{array}$

No exemplo da língua venda, em (27), o verbo inergativo amb "falar" seleciona o DP sujeito Mukasa. Além disso, a esse verbo é adjungido o morfema aplicativo alto $\{-e l-\}$, cuja função é introduzir o argumento Katonga. Ao final desse processo morfossintático, o verbo amb "falar" passa de inergativo para transitivo. Nesse exemplo, o objeto aplicativo Katonga recebe papel temático de beneficiário atribuído pelo núcleo aplicativo alto. Concluindo, a diferença semântica entre os dados acima é que, no exemplo (27), não há dois objetos em uma relação de posse, como ocorre em (24) e (25). Na próxima seção o intuito é o de apresentar o sistema de marcação de Caso em Tenetehára.

\section{SISTEMA DE MARCAÇÃO DE CASO EM TENETEHÁRA ${ }^{17}$}

Assim como ocorre nas demais línguas Tupí-Guaraní, os sintagmas nominais em Tenetehára não recebem desinências de Caso para distinguir os DPs na função sintática de sujeito e de objeto. As funções sintáticas são codificadas por meio da série de prefixos

Quadro 2

Marcadores nominativos e pronomes pessoais

\begin{tabular}{|c|c|c|c|}
\hline Pessoas & $\begin{array}{l}\text { PRONOMES PESSOAIS } \\
\text { INDEPENDENTES }\end{array}$ & $\begin{array}{c}\text { PRONOMES PESSOAIS } \\
\text { CLÍTICOS }\end{array}$ & $\begin{array}{c}\text { PREFIXOS PESSOAIS } \\
\text { NOMINATIVOS }\end{array}$ \\
\hline eu & ihe & he & a- \\
\hline nós INCLUSIVO $_{\text {I }}$ & dane & dane & $\mathrm{si}^{-} \sim \mathrm{da}-$ \\
\hline nós ExCLUSIYO & ure & ure & uru- $\sim$ oro- \\
\hline tu & ne & ne & re- \\
\hline vós & pe & pe & pe- \\
\hline ele & - & - & $\mathrm{u}^{\sim} \sim^{\sim} \mathrm{O}-\sim \mathrm{W}-$ \\
\hline
\end{tabular}

Fonte: Duarte, 2007, p. 44

${ }_{17}$ Os dados dessa seção foram retirados de Duarte (2007). 
nominativos e absolutivos e através dos pronomes pessoais que, em geral, vêm proclíticos ao verbo. Estes prefixos podem ser visualizados a seguir:

Quadro 3

Prefixos pessoais absolutivos

\begin{tabular}{c|c|c|c}
\hline PESSOAS GRAMATICAIS & $\begin{array}{c}\text { RAIZ INICIADA EM } \\
\text { CONSOANTE }\end{array}$ & $\begin{array}{c}\text { RAIZ INICIADA EM } \\
\text { VOGAL }\end{array}$ & TRAÇO DISTINTIVO \\
\hline $19 / 2 a$ & $\emptyset-$ & $r-$ & {$[+P E S S O A]$} \\
$3 a$ & $i-$ & $h-$ & {$[-P E S S O A]$} \\
\hline
\end{tabular}

Fonte: Camargo, 2010, p. 27

Duarte (2007) mostra que, na língua Tenetehára, ocorre cisão de Caso condicionada pela natureza do NP. Ou seja, quando o sujeito (A) de transitivo é mais alto do que o objeto $(\mathrm{O})$ na hierarquia de pessoa ${ }^{18}$, o sistema nominativo é acionado. Por sua vez, quando o objeto $(\mathrm{O})$ é mais alto do que o sujeito (A) de transitivo, o sistema absolutivo é acionado. Veja os exemplos que se seguem.

\section{Sistema Nominativo $(\mathrm{A}>\mathrm{O})$}

$\begin{array}{lcl}\text { ihe } & \text { a-zuka-ràm } & \text { zawar } \\ \text { eu } & \text { 1-matar-FUt } & \text { onça } \\ \text { "Eu matarei a onça" } & \end{array}$

(28b) ne re-zuka-ràm zawar

tu 2-matar-Fut onça

"Tu matarás a onça”

(28c) a'e u-zuka-ràm zawar

ele 3-matar-Fut onça

"Ele matará a onça"

18 A língua Tenetehára, assim como as demais línguas da família Tupí-Guaraní, é sensível à hierarquia de pessoa. A primeira pessoa é mais alta do que a segunda, que é mais alta do que a terceira focal e, por fim, é mais alta do que a terceira não focal. Acompanhando intuição de Rodrigues (1990) e seguindo Duarte (2007), pode-se formalizar esta hierarquia da seguinte maneira: $1>2>3^{+\mathrm{FOC}}>3^{-\mathrm{FOC}}$. 
Sistema Absolutivo $(\mathrm{O}>\mathrm{A})$

$(29 a)$

$$
\begin{array}{ll}
h e=\emptyset-z u k a-\grave{a} m & \text { zawar } \\
\text { me=ABS-matar-FUT } & \text { onça }
\end{array}
$$

"A onça me matará"

$$
\begin{array}{lll}
\text { (29b) } & \text { ne }=\varnothing-z u k a-\text { ràm } & \text { zawar } \\
\text { te }=\text { ABS-matar-FUT } & \text { onça }
\end{array}
$$

"A onça te matará"

De acordo com Duarte (2007), a língua Tenetehára também possui cisão de Caso condicionada pela natureza do verbo da seguinte forma: por um lado, o sujeito (A) de verbo transitivo alinha-se com o sujeito $(\mathrm{Sa})$ de verbo intransitivo ativo; por outro lado, o objeto $(\mathrm{O})$ de transitivo nivela-se com o sujeito de verbo inativo. Veja os exemplos a seguir.

Sistema Nominativo $(\mathrm{A}=\mathrm{Sa})$

$\begin{array}{lll}\text { ihe } & \text { a-esak } & \text { zawar } \\ \text { eu } & \text { 1-ver } & \text { onça } \\ \text { "Eu vi a onça" } & \end{array}$
(30b) ne re-(e)sak zawar
tu 2-ver onça

"Tu viste a onça"
(30c) a'e u-esak zawar

ele 3-ver onça

"Ele viu a onça"
(31a) ihe a-wata
eu 1-caminhar
"Eu caminhei"


(31b) ne re-wata

tu 2-caminhar

"Tu caminhaste"

(31c) a'e u-wata

ele 3-caminhar

"Ele caminhou"

Sistema Absolutivo $(\mathrm{O}=\mathrm{So})$
he $=r$-esak
zawar
me $=$ ABs-ver
onça

"A onça me viu"

$(32 b)$

$\begin{array}{ll}\text { ne=r-esak } & \text { zawar } \\ \text { te=ABS-ver } & \text { onça } \\ \text { "A onça te viu" } & \end{array}$

(33a) he=r-urywete

$\mathrm{eu}=\mathrm{ABS}$-alegre

"Eu estou alegre"

(33b) ne=r-urywete

$\mathrm{tu}=\mathrm{ABS}$-alegre

“Tu estás alegre”

Em suma, o sujeito (A) de transitivos alinha-se com sujeito (Sa) de verbos ativos (ocasionando a realização dos prefixos nominativos); por sua vez, o objeto (O) de transitivos nivela-se com o sujeito de verbos inativos (So) (permitindo a manifestação dos prefixos absolutivos). Duarte (2007: 53) ilustra este sistema da seguinte forma: 
Quadro 4

Sistema cindido de codificação dos argumentos nucleares em orações independentes

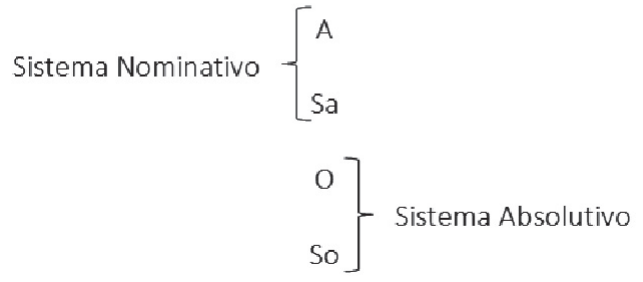

Na próxima seção, o objetivo será o de apresentar dados da língua Tenetehára e relacioná-los ao quadro teórico já exibido.

\section{ANÁLISE E PROPOSTA TEÓRICA}

A estruturação dessa seção foi feita da seguinte maneira: (i) incorporação de objeto com e sem diminuição de valência; (ii) diminuição de valência verbal por meio do morfema antipassivo $\{-p u r(u)\}$; e (iii) aumento de valência verbal por meio do morfema aplicativo $\{-\operatorname{er}(u)\}$.

\subsection{Incorporação de objetos}

De acordo com Castro (2007) e Duarte \& Castro (2010), a diminuição de valência de verbos transitivos em contextos de incorporação de objeto, acompanhando Baker (1988), pode ser observada como nos exemplos abaixo.

$$
\begin{aligned}
& \text { u-hyw u-pya } \\
& \text { 3-limpar } \quad \text { coRR-barriga } \\
& \text { "(Ele) limpou a barriga (dele mesmo)" } \\
& \text { HARRISON (2007) }
\end{aligned}
$$


Em (34), temos o verbo transitivo hyw "limpar", o qual seleciona dois argumentos nucleares: um sujeito de terceira pessoa recuperável pelo prefixo $\{u-\}^{19}$ e o argumento interno py'a "barriga". Já em (34b), podemos observar que o argumento interno se incorpora à raiz verbal ${ }^{20}$, tornando tal predicado monoargumental, o qual seleciona apenas o sujeito de terceira pessoa. Vejamos outro exemplo a seguir.

u-kwaw ma'e a'e
3-saber coisa
"(Ele) sabe coisas"

CASTRO (2010)

$\begin{aligned} & \text { u-mae-kwaw } \\ & \text { 3-coisa-saber }\end{aligned}$
"(Ele) sabe coisas"

CASTRO (2010)

Em (35a), temos o verbo transitivo kwaw "saber", o qual seleciona dois argumentos: o sujeito de terceira pessoa e o objeto ma'e "coisa". Já em (35b), pode-se observar o predicado intransitivo ma'e-kwaw "saber coisas", cujo objeto do verbo transitivo inicial foi incorporado. Desse modo, nos exemplos do Tenetehára em (34) e (35), observa-se que o $\mathrm{NP}_{\text {objeto }}$ se incorpora ao verbo lexical, transformando-os em inergativos. Entretanto, nos contextos

19 Salienta-se que o Tenetehára é uma língua de sujeito nulo (pro-drop), permitindo que o argumento externo do verbo transitivo seja apenas referido no verbo pelo prefixo nominativo de terceira pessoa.

${ }^{20} \mathrm{O}$ argumento incorporado não pode carregar morfemas de concordância, nem apresentar determinantes, pois precisa ser um $\mathrm{NP}_{\mathrm{nu}}$. Assim sendo, o argumento interno $u$ - $p$ y'a "barriga dele" deve perder o prefixo correferencial $\{u-\}$. Este fato sinaliza que, de fato, a premissa incorporada não pode carregar morfemas anafóricos. 
de ascensão do possuidor, além de haver incorporação, a valência do verbo não se altera. Nessa linha de investigação, apenas parte do objeto pode se incorporar a um verbo transitivo, o qual não passa a monoargumental. A fim de comprovar tal afirmação, têm-se os dados abaixo:
(36a)
o-ok awa
miar
i-àkàg
3-tirar homem
animal
poss-cabeça
"O homem tira a cabeça do animal"
CASTRO (2010)

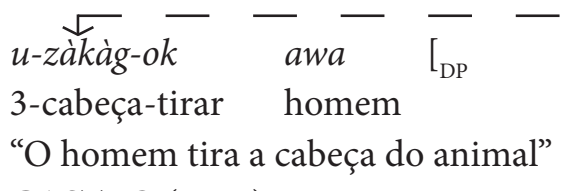
CASTRO (2010)

Em (36a), o verbo transitivo 'ok "tirar" seleciona o sujeito awa "homem" e o objeto miar i-àkàg "cabeça do animal”. Em (36b), por sua vez, há um processo de incorporação de parte do objeto, a saber: o núcleo do sintagma possessivo $i$-àkàg ${ }^{21}$ "cabeça". Assim, o argumento possuído do sintagma possessivo se incorpora à raiz verbal. No final do processo, o possuidor do sintagma possessivo é promovido a objeto da sentença. Pode-se observar essa mesma incorporação sem diminuição de valência em outros exemplos, conforme (37) e (38).
u-kutuk w-a'yr
h-eme
3-furar
CORR-filho
POss-lábio
"(Ele) fura o lábio do (próprio) filho"

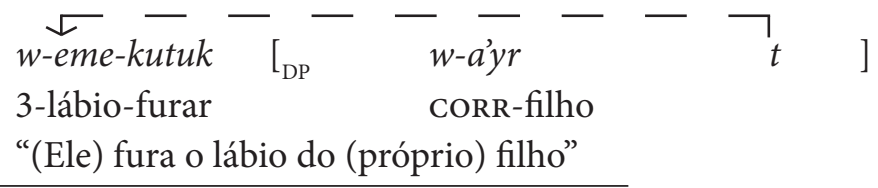

${ }^{21} \mathrm{O}$ argumento incorporado não pode carregar morfemas de concordância, nem apresentar determinantes, pois precisa ser um $\mathrm{NP}_{\mathrm{nu}}$. Assim sendo, a premissa possuída $i$-àkàg "cabeça dele" deve perder o prefixo denotador de posse $\{i$ - $\}$. Este fato sinaliza que, de fato, o argumento incorporado não pode carregar morfemas anafóricos. 
u-kixi $\quad w$-a'yr i-po

3-cortar CORR-filho POss-mão

"(Ele) corta a mão do (próprio) filho"

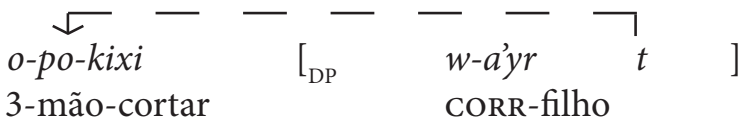

"(Ele) cortou a mão do (próprio) filho"

CASTRO (2010)

Em (37a) e (38a), tem-se os verbos transitivos kutuk "furar" e kuxi "cortar" que selecionam sujeitos de terceira pessoa e os objetos a’yr h-eme "lábio do filho" e a'yr i-po "mão do filho", respectivamente. Em (37b) e (38b), por sua vez, existe um processo morfossintático de incorporação do NP possuído a’yr "filho" no núcleo do verbo. Ou seja, o argumento possuído do sintagma possessivo se desloca de sua posição de base, incorporando-se à raiz verbal. Finalizado o fenômeno, o possuidor do sintagma possessivo é alçado a objeto da sentença.

Observe que, nos exemplos de (36) a (38), diferentemente do que ocorre em (34) e (35), não há alteração no número de argumentos, uma vez que há incorporação de apenas parte do objeto nos verbos 'ok "tirar", kutuk "furar" e kixi "cortar", não provocando redução de valência ${ }^{22}$. Contudo, esses dois processos sintaticamente distintos ilustram o contexto em que o objeto se incorpora ao verbo conforme os pressupostos teóricos de Baker (1988). Assim sendo, o movimento do objeto para dentro da matriz fonológica do verbo deixa um traço na posição em que é gerado de forma a atender ao Princípio da Categoria Vazia (ECP) e evidenciando a aplicação da Hipótese da Uniformidade de Atribuição Theta (UTAH). Na subseção seguinte, investigamos o morfema antipassivo $\{-\operatorname{pur}(u)\}$.

\footnotetext{
${ }^{22}$ Pode-se notar que, para se incorporar, o argumento deve ser um $\mathrm{NP}_{\mathrm{nu}}$. Assim sendo, os argumentos internos dos exemplos de (30) a (32) devem perder o prefixo atribuidor de Caso genitivo $\{i-\sim h-\}$.
} 


\subsection{Morfema antipassivo \{-pur(u)\}}

A fim de apresentar os contextos de ocorrência do morfema de voz antipassiva em Tenetehára e a consequente diminuição de valência de predicados transitivos, fornecemos os seguintes exemplos:

$\begin{array}{lll}\text { (39a) awa } & \text { w-àro } & \text { Murari } \\ \text { homem } & \text { 3-esperar } & \text { Murari } \\ \text { "O homem espera Murari" }\end{array}$

CASTRO (2010)

$\begin{array}{llll}\text { awa } & \text { i-puru-wàro-wer } & \text { Murari } & \text { r-ehe } \\ \text { homem } & \text { ABS-APASS-esperar-DESID } & \text { Murari } & \text { C-PSP } \\ \text { "O homem deseja esperar Murari” } & & \end{array}$

CASTRO (2010)

No exemplo (39a), o predicado transitivo àro "esperar" seleciona dois argumentos nucleares: o DP sujeito awa "homem" e o DP objeto Murari. Ressaltamos que, nessa oração, o sistema de Caso acionado é o nominativo-acusativo, uma vez que o verbo àro "esperar" concorda com o DP sujeito awa "homem". Por sua vez, em (39b), o predicado àro "esperar" recebe o morfema antipassivo $\{-\operatorname{pur}(u)\}$, que tem a função de tornar monoargumental o verbo da oração. Por conseguinte, o verbo transitivo àro "esperar" passa a selecionar apenas o DP sujeito awa "homem". Adicionalmente, o DP objeto Murari da oração inicial é demovido a oblíquo em (39b), sendo selecionado pela posposição lexical (=predicadora) rehe "em".

A afirmação de que a alternância ativa/antipassiva reverbera em mudança de aspecto verbal é novamente ratificada pelo fato de que em (39b) emerge o morfema de aspecto desiderativo $\{-$ wer $\}$. Nessa linha de investigação, pode-se postular que o aspecto verbal, também em Tenetehára, é sensível à alternância ativa/antipassiva. Ao final do processo, o sistema de Caso é alterado de nominativo-acusativo para (ergativo)-absolutivo. Veja outro exemplo a seguir. 
$\begin{array}{lll}\text { w-exak } & \text { Kahiw } & \text { ma'eputyr } \\ \text { 3-ver } & \text { Kahiw } & \text { flor }\end{array}$

"Kahiw vê a flor"

CASTRO (2010)

(40b) i-puru-exak-wer

Kahiw ma'eputyr r-ehe a'e

ABS-APASS-ver-DESID Kahiw flor C-PSP ele

"Kahiw deseja ver a flor"

CASTRO (2010)

Em (40a), pode-se observar que o verbo transitivo exak "ver" seleciona dois argumentos: o DP sujeito Kahiw e o DP objeto ma'eputyr "flor". Salientamos que o sistema de Caso acionado é o nominativo-acusativo. Já em (40b), o morfema antipassivo $\{-p u r(u)\}$, cuja função é diminuir a valência do verbo transitivo exak "ver", é adjungido ao verbo. Logo, o predicado transitivo da oração original passa a intransitivo porque seleciona como argumento nuclear apenas o DP sujeito Kahiw. O DP objeto ma’eputyr "flor" da oração inicial passa, em (40b), a ser argumento da posposição lexical rehe "em". Observa-se também a ocorrência do morfema de aspecto desiderativo \{-wer\}. Adicionalmente, o sistema de Caso é alterado de nominativo-acusativo para (ergativo)-absolutivo.

Note-se, nos exemplos de (39) e (40), que, quando os verbos transitivos recebem o morfema $\{-\operatorname{pur}(u)\}$, o argumento interno é demovido por meio de uma posposição, passando a oblíquo. Nossa hipótese, conforme já dissemos, é a de que o DP objeto das orações iniciais passe a ser o argumento da posposição predicadora rehe "em".

Para uma melhor descrição da alternância voz ativa e antipassiva em Tenetehára, tem-se a seguinte sequência: (i) realização do morfema APAss $\{-\operatorname{pur}(u)\}$; (ii) o verbo transitivo, consequentemente, se torna intransitivo; (iii) objeto é demovido por meio de uma posposição; (iv) emerge o morfema desiderativo $\{$-wer $\}$ junto ao verbo; e (v) os sujeitos dos verbos transitivos iniciais recebem o Caso absolutivo em detrimento do Caso nominativo. A fim de evidenciar os passos de construção de voz antipassiva em Tenetehára, arrolamos mais dois exemplos que se seguem: 
"O avô deseja cozinhar a carne"

Observe que, no exemplo (41a), o predicado transitivo mimo "cozinhar" figura como um verbo que seleciona dois argumentos nucleares: o DP sujeito tàmuj "avô" e o DP objeto ma'erukwer "carne". O sistema de marcação de Caso é, nesse exemplo, o nominativo-acusativo. Isso pode ser constatado porque o verbo mimoj "cozinhar" concorda com o DP sujeito tàmuj "avô". Todavia, em (41b), a presença do morfema antipassivo $\{-p u r(u)\}$ faz com que o verbo mimoj "cozinhar" seja reanalisado como monoargumental, passando a selecionar apenas o DP sujeito təmu "avô". Além disso, o DP objeto ma'erukwer "carne" da oração inicial é demovido a oblíquo, sendo selecionado pela posposição lexical rehe "em".

A afirmação de que o aspecto verbal é sensível à alternância ativa/antipassiva promove, mais uma vez, uma sustentabilidade, porquanto, em (41b), emerge o morfema de aspecto desiderativo $\{-w e r\}$. Nessa linha de investigação, em (41a), o DP objeto ma’erukwer "carne" é necessariamente afetado pela ação expressa pelo predicado verbal. Já em (41b), o DP que corresponde ao objeto da oração original, agora encabeçado pela posposição rehe "em", não é necessariamente afetado pela ação do DP sujeito tàmuj "avô". Ao final do mecanismo morfossintático, o sistema de Caso é alterado do nominativo-acusativo para o (ergativo)-absolutivo. O exemplo agramatical abaixo ilustra essa construção de voz antipassiva sem a ocorrência do morfema aspectual.

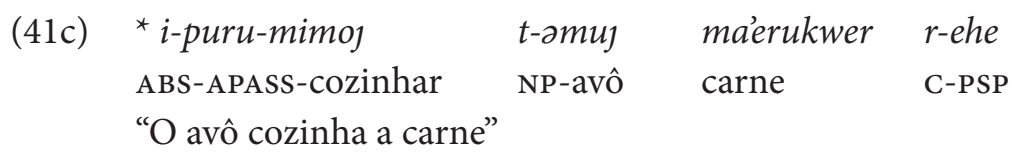


Veja mais um exemplo em que se pode visualizar, em Tenetehára, a ocorrência ora da voz ativa, ora da voz antipassiva:
(42a) kwarer
u-kwaw
u-myrypar
menino
3-conhece
CORR-amigo
"O menino conhece seu (próprio) amigo"
i-puru-kwaw-wer
kwarer
u-myrypar
r-ehe
ABS-APASS-conhecer-DESID menino
CORR-amigo
C-PSP
"O menino deseja conhecer seu (próprio) amigo"

O dado em (42a) permite observar que o verbo transitivo kwaw "conhecer" seleciona dois argumentos nucleares: o DP sujeito kwarer "menino" e o DP objeto umyrypar "amigo". Ressalto que o sistema de Caso acionado, nessa sentença, é o nominativo-acusativo. No entanto, em (42b), o morfema antipassivo $\{-\operatorname{pur}(u)\}$, cuja função é diminuir a valência do verbo transitivo kwaw "conhecer", é adjungido ao verbo. Por isso, o predicado transitivo da oração original passa a intransitivo, selecionando apenas o DP sujeito kwarer "menino". Adicionalmente, emerge o morfema de aspecto desiderativo $\{$-wer\}. No final desse processo morfossintático, o sistema é alterado do nominativo-acusativo para o (ergativo)-absolutivo. Na próxima subseção, investigamos o escopo do morfema $\{\operatorname{er}(u)-\}$, o qual é, em geral, sufixado a predicados monoargumentais.

\subsection{Morfema aplicativo $\{\operatorname{er}(u)-\}$}

O uso do termo "aplicativo" e a análise para o morfema comitativo das línguas da família Tupí-Guaraní foi usado inicialmente por Vieira (2001). Descritivamente, o morfema $\{e r(u)$ - $\}$ constitui um expediente de aumento de valência de verbos que possuem apenas um argumento. Tal unidade gramatical parece ocorrer tanto em contextos de verbos inacusativos como de inergativos, atribuindo papel temático de comitativo ao argumento inserido. Observe os seguintes exemplos abaixo: 
(43a) a'e u-'ar

3 3-cair

"(Ele) caiu"

CASTRO (2010)

(43b) w-eru-'ar $\quad w$-a'yr

3-COM-cair CORR-filho

"Ele caiu com o filho"

CASTRO (2010)

Em (43a), há o verbo inacusativo 'ar "cair", que seleciona apenas um argumento nuclear: o sujeito referido pelo prefixo nominativo de terceira pessoa $\{u$ - $\}$. Já em (43b), nota-se que o verbo inacusativo 'ar "cair" recebe o morfema $\{e r(u)-\}$, cuja função é introduzir o objeto a'yr "filho", que, por seu turno, recebe a propriedade semântica de comitativo. Veja mais um exemplo com verbo inacusativo:
$(44 \mathrm{a})$
$\begin{array}{ll}\text { awa } & \text { u-màno } \\ \text { homem } & 3 \text {-morrer }\end{array}$
"O homem morreu"
CASTRO (2010)
(44b) he r-apihar a-(e)ru-màno
1 Poss-semelhantes 1-COM-morrer
"Eu (devo) morrer juntamente com os meus semelhantes" BOUDIN (1966)

Em (44a), por um lado, há o verbo inacusativo màno "morrer", que seleciona apenas um argumento nuclear: o sujeito awa "homem"; por outro lado, em (44b), nota-se que esse verbo recebe o morfema $\{\operatorname{er}(u)$ - $\}$, cuja função é a de introduzir o argumento a’yr "filho". Esse objeto recebe o atributo semântico de comitativo. A seguir, apresentamos a ocorrência do morfema $\{e r(u)-\}$ com verbos inergativos. 
(45a)

kwarer u-hapukaj

menino 3-gritar

"O menino grita"

CASTRO (2010)

(45b) w-eru-hapukaj zawar

3-COM-gritar cachorro

"Ele grita com cachorro (está no seu regaço)"

CASTRO (2010)

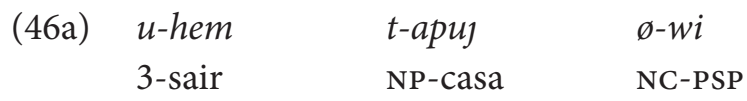

"(Ele) saiu de casa"

CASTRO (2010)

(46b) w-eru-hem u-hy

3-COM-sair CORR-mãe

"Ele saiu com a (própria) mãe"

CASTRO (2010)

Os exemplos em (45a) e (46a) exibem os verbos inergativos hapukaj "gritar" e hem "sair", os quais selecionam o sujeito kwarer "menino" e o sujeito de terceira pessoa $\{u$ - $\}$ "ele”, respectivamente. Já em (45b) e (46b), o morfema $\{$ er $(u)-\}$ introduz os objetos apuj "casa" e hy "mãe", respectivamente. Portanto, os exemplos dessa subseção apontam para o seguinte fato: o morfema $\{\operatorname{er}(u)-\}$ tem a propriedade de introduzir um argumento objeto na função semântica de comitativo, situação sintática em que os verbos inergativos e inacusativos passam a transitivos.

Adotando a proposta de Pylkkänen (2002), e as evidências reunidas por Vieira (2010) para as línguas Tupinambá e Guaraní, pode-se propor que em Tenetehára o morfema $\{e r(u)$ - $\}$ é a evidencia morfológica do núcleo aplicativo alto por duas razões: (i) sintaticamente ele se afixa a verbos intransitivos (inacusativos e inergativos); (ii) semanticamente não há uma relação de transferência de posse entre os dois argumentos do verbo. Nesse sentido, a 
língua Tenetehára se assemelha à língua venda, conforme foi mostrado na subseção 2.4. A seguir, o objetivo é tecer as considerações finais.

\section{CONSIDERAÇÕES FINAIS}

Neste texto, discutimos a alternância de valência em Tenetehára. A partir desse epifenômeno, demonstramos algumas construções relacionadas ao tema central. Desenvolvemos, assim, a análise de que nas construções de alçamento do possuidor, apenas parte do objeto, a saber, o NP possuído, pode se incorporar ao núcleo do $v \mathrm{P}$. O resultado desse processo não altera a estrutura transitiva inicial, ou seja, nas construções de alçamento do possuidor não existe diminuição de valência, apesar de haver incorporação.

Adicionalmente, buscamos corroborar a existência da voz antipassiva em Tenetehára, assim como pode ser observado em outras línguas Ergativas e Acusativas. Como já dito, alguns autores tais como Silverstein (1976), Dixon (1979) e Spencer (1991) argumentam que existe um mapeamento biunívoco, em que as línguas acusativas apresentam a voz passiva enquanto que as línguas ergativas exibem a voz antipassiva. De forma contrária, Heath (1976), Postal (1977), Davies (1984), Givón (1984), Lazard (1989), Lidz (1996), Lacadema (2000), Bligth (2004), entre outros, tentam deixar evidente que tanto as línguas ergativas apresentam construções antipassivas quanto as línguas acusativas exibem uma estrutura que parece corresponder às antipassivas. Assumimos essa última postura teórica nesse trabalho. Como pôde ser visto, a voz antipassiva parece produzir os mesmos efeitos na morfologia, na sintaxe e na semântica tanto em línguas ergativas como em línguas acusativas, tais como o inglês, o francês e o português.

Já que as evidências mostradas nesse artigo apontam para o fato de que ocorrem contextos de voz antipassiva em línguas acusativas, como afirmam os autores acima, é interessante observar que a Gramática Tradicional não menciona a voz antipassiva ao denominar essas estruturas como voz ativa em contextos de "objeto direto preposicionado". 
Finalmente investigamos a ocorrência do morfema $\{-\operatorname{er}(u)\}$, o qual, acompanhando Pylkkänen (2002) e Vieira (2010), evidenciamos ser a manifestação de um núcleo aplicativo alto em Tenetehára.

\section{REFERÊNCIAS BIBLIOGRÁFICAS}

ALDRIDGE, Edith. Antipassive and ergativity in tagalog. In: Lingua, v. 10, p. 1016-1028, 2012.

ALLEN, Shanley E. M. Noun Incorporation in Eskimo: Postpositions and Case Marking. In: McGill Working Papers in Linguistics, v. 5, n. 2, p.1-39, 1988.

BAKER, Mark C. Incorporation: a theory of grammatical function changing. Chicago: University of Chicago Press, 1988.

BLIGHT, Ralph Charles. Head Movement, Passive and Antipassive in English. Tese (Doutorado). Austin: University of Texas at Austin, 2004.

BOUDIN, Max Henry. O simbolismo verbal primitivo. Faculdade de Filosofia,Ciencias e Letras de Presidente Prudente. Departamento de Publicações - Serie Ciencias Sociais. Presidente Prudente, 1966.

BUENO, Silveira. Vocabulário tupi-guarani-português. 6. ed. São Paulo: Éfeta, 1998.

CAMARGOS, Quesler Fagundes. Estruturas causativas em Tenetehára: uma abordagem minimalista. 2013. 187 f. Dissertação (Mestrado em Linguística Teórica e Descritiva) - Faculdade de Letras, Universidade Federal de Minas Gerais, Belo Horizonte, 2013.

CASTRO, Ricardo Campos. Interface morfologia e sintaxe em Tenetehára. (Dissertação de Mestrado). Universidade Federal de Minas Gerais, Belo Horizonte, 2007. 
CASTRO, Ricardo Campos. Arquivo pessoal. Belo Horizonte. Não publicado, 2010.

DAVIES, William. Antipassive: Choctaw evidence for a universal characterization. In.: PERLMUTTER, David; ROSEN, Carol. Studies in Relational Grammar. Chicago: The University of Chicado, 1984.

DE VRIES, M. The syntax of relativization. Utrecht: LOT, 2002.

DIXON, Robert Malcolm Ward. Ergativity. Language, n. 55, p. 59-138, 1979.

DUARTE, Fábio Bonfim. Estudos de morfossintaxe em Tenetehára. Belo Horizonte: Faculdade de Letras, 2007.

DUARTE, Fábio Bonfim; CASTRO, Ricardo Castro. Incorporação nominal, inergatividade e estrutura causativa em Tenetehára. In: CABRAL, Ana Suelly Arruda; RODRIGUES, Aryon DallIgna. Línguas e Culturas Tupí. Brasília/ Campinas: Curt Nimuendajú, 2010.

DUARTE, Fábio Bonfim . O que difere uma língua ergativa de uma língua nominativa?. In: Revista estudos da linguagem, v. 20, n.2, 2012a.

DUARTE, Fábio Bonfim. Tenetehára: A predicate-fronting language. In: The Canadian Journal of Linguistics / La revue canadienne de linguistique, v. 57, p. 359-386, 2012b.

FOLEY, William; VAN VALIN, Robert. Information Packaging in the Clause' in T Shopen. In: Language Typology and Syntactic Description, Cambridge University Press, v. 1, 1985.

FRANCHETTO, Bruna A Ergatividade Kuikúro (Karibe): Algumas Propostas de Análise. In: Caderno de Estudos Lingüísticos, Campinas: UNICAMP, v. 18, n. 1, p. $57-78,1990$. 
GIVÓN, Talmy. Syntax: a functional-typological introduction 1. Amsterdam: John Benjamins, 1984.

HALE, Ken; KEYSER, Samuel Jay. On argument structure and the lexical expression of syntactic relations. In: HALE, Ken; KEYSER, Samuel Jay (Org.) The view from building 20. Cambridge: MIT Press, 1993.

HALE; KEYSER. Prolegomenon to a theory of argument structure. Cambridge: MIT Press, 2002.

HARRISON, Carl. Verb prominence, verb initialness, ergativity and typological disharmony in Guajajara. In: DERBYSHIRE, Desmond C.; PULLUM, Geoffrey K. (Ed.). Handbook of Amazonian Languages. Berlin: Mouton de Gruyter, 1986. p. 407-439.

HARRISON, Carl. Arquivo pessoal. Carolina do Norte. Não publicado, 2007.

HEATH, Jeffrey. Antipassivization: a functional typology. Berkeley Linguistics Society, v. 2, p. 202-211, 1976.

HERSLUND, Michael. Passive and Antipassive in a Functional Description of French Reflexive Verbs. In: Hermes, Journal of Linguistics, n. 19, p. 75-92, 1997.

LACADEMA, Alfonso. Antipassive Constructions in the Maya Glyphic Texts. In: Revista Española de Antropología Americana, Madrid, n. 30, p. 27-85, 2000.

LAZARD, Gilbert. Transitivity and markedness: the antipassive in accusative languages. In.: TOMIĆ, M. Markedness in Synchrony and Diachrony, Mouton de Gruyter, Berlin, 1989 p. 309-331. 
LIDZ, Jeffrey. Dimensions of Reflexivity. Delaware: Universidade de Delaware, 1996. (Tese de Doutorado).

MARANTZ, Alec. No escape from syntax: don't try morphological analysis in the privacy of your own lexicon. In: Penn Working Papers in Linguistics, v. 4, n. 2, p. 201-225, 1997.

NAVARRO, Eduardo de Almeida. Recensão Crítica à: Fonologia e Gramática do Nheengatú: a língua geral falada pelos povos Baré, Warekena e Baniwa. CRUZ, Aline. 1.ed .Utrecht, Países Baixos: LOT, 2011. In: Língua e Literatura, n. 30, 2012

PALMER, F. Grammatical Roles and Relations. Cambridge University Press, 1994.

POLINSKY M. Antipassive constructions. In: HASPELMATH, M; DRYER, M. S.; GIL, D; COMRIE, B. The World Atlas of Language Structures. Oxford: Oxford University Press, 2005.

POSTAL, Paul. Antipassive in french. In: Lingvisticae e Investigationes, v. 1. p. 333-374, 1977.

PYLKKÄNEN, Liina. Introducing Arguments. Tese (Doutorado).Cambridge: The MIT Press, 2002.

RODRIGUES, Aryon Dall'Igna. Relações internas na família linguística Tupí-Guaraní. In: Revista de Antropologia, v. 27/28, p. 33-53, 1985.

RODRIGUES, A. D. You and I=neither you nor I: the personal system of Tupinambá. In: Payne, D. L. (Org.). Amazonian linguistics: studies in lowland South American languages. Austin: University of Texas Press, 1990.

SEKI, Lucy. Gramática do Kamaiurá: Língua Tupi-Guarani do Alto Xingu. Campinas: Editora da Unicamp; São Paulo: Imprensa Oficial, 2000. 
SILVERSTEIN, Michael. Hierarchy of features and ergativity. DIXON, R. M. W. Grammatical Categories in Australian Languages. Universidade Nacional Australiana, 1976.

SPENCER, Andrew. Morphological theory: an introduction to word structure in generative grammar. Blackwell Editor, 1991.

VIEIRA, Márcia Maria Damaso. A natureza transitiva das sentenças possessivas em Mbyá-Guarani. In Queixalós (Org.). Des noms et des verbes en tupi-guarani. p. 67-86. München: Lincom, 2001.

VIEIRA, Márcia Maria Damaso. Os núcleos aplicativos e as línguas indígenas brasileiras. In: Revista de Estudos da Linguagem da Faculdade de Letras da UFMG, v. 18, n. 1, p. 141-164, 2010.

WHALEY, Lindsay J. An Introduction to Language Typology: The Unity and Diversity of Language. New York: SAGE Publications, 1997. 
